\title{
An economic analysis of the observing response in the pigeon
}

\author{
JAMES ALLISON \\ Indiana University, Bloomington, Indiana
}

\begin{abstract}
Pigeons buy information about the price of access to food by pecking an observing response key. This response produces an external cue that signals how many pecks at another key will suffice to open the food hopper. The pigeon buys less information about the price of food as the price of the information rises, in accordance with the demand law of economics. Its demand for information grows more responsive to price as the price of the information rises, and the range of possible food prices decreases. Because they do not affect the number of pecks required to open the hopper, pecks at the observing key seem only to raise the overall price of access to food. Additional research might reveal the adaptive function of the observing response by examining how efficiently the pigeon exploits each access to food, and the extent to which it overpays the nominal price of access.
\end{abstract}

Laboratory experiments suggest that under certain circumstances, the hungry pigeon is prepared to incur a large behavioral cost in exchange for information about the current price of the chance to eat. In accordance with the demand law of economics, the pigeon buys less of the information as the unit cost of the information rises. The consumption of price information thereby resembles the consumption of such items as food, water, and drugs on the part of such laboratory animals as rats, fish, and monkeys (Allison, 1983). Another point of resemblance is that the pigeon's demand for information grows more responsive to price-more "price-elastic"-as the price of the information rises. The latter feature is typical of demand functions measured in experiments on animals as consumers (Allison 1979, 1981, 1983, 1986; Hursh, 1980; Lea, 1978). Perhaps most striking, the pigeon's demand for price information grows more elastic as the range of possible food prices grows smaller.

Each of these facts about the pigeon's demand for price information may seem entirely reasonable. Nevertheless, there remains considerable doubt about the specific use the pigeon makes of such information. Indeed, if one adds the behavioral cost of the information to the behavioral price of the chance to eat, it appears that the purchase of information serves only to raise that price. Thus, although the observing response seems to constitute an economic good, it remains unclear what good the pigeon derives from the observing response. This paper supports all of these characterizations of the observing response in the pigeon by means of some new analyses of data already published.

The prototypical experiment (Hendry, 1969) maintained each of three pigeons at $75 \%$ to $80 \%$ of the body weight established during the pre-experimental period, a period

\footnotetext{
I thank Alison Buxton and James A. Dinsmoor for their valuable comments on the first draft. Address correspondence to James Allison, Department of Psychology, Indiana University, Bloomington, IN 47405.
}

of free access to food. At the start of each experimental session, the hungry pigeon faced two translucent keys on the wall of the test chamber, plastic back-lighted disks about 1 in. wide. One was a white "food" key, the other a dark "observing" key.

The pigeon could get food according to a prearranged schedule only by pecking the white food key a certain number of times. On randomly selected occasions, the schedule required only 20 food-key pecks for access to the food hopper. In this type of setting the hopper swings up to a lighted aperture and gives access to its contents for a fixed duration, typically 2 to $6 \mathrm{sec}$, then swings back down. On the other half of the occasions, the schedule required 80 food-key pecks for the same access to food. Because the current price, 20 or 80 pecks, was selected at random, the pigeon faced some uncertainty about the current price of the chance to eat.

Of course the pigeon could learn something about the current price if it could manage to keep track of the number of food-key pecks since the last access. Each peck should produce considerable feedback to the pigeon: the typical key is mounted on a light spring, operates in response to a "natural" peck, and is wired to a relay that produces a clearly audible click with each peck. And if the food remains inaccessible after 20 pecks at the white food key, then the current access price must be 80 pecks rather than 20.

Alternatively, 4 pecks on the dark observing key would buy price information that would be more definite and more manageable. Upon the fourth peck at the dark observing key, both keys would turn red if the current price were 20 food-key pecks, green if 80 . Both would stay red or green until the pigeon performed the required number of food-key pecks, 20 or 80 , at which time the food would become accessible for the usual duration. The keys would then return to their initial state, white for the food key and dark for the observing key. The schedule would then select at random the next price of access, 20 or 80 food- 
key pecks. That selection would also set the next chance for the pigeon to observe the current access price at the same information cost as before, 4 pecks on the dark observing key. Such experimental sessions typically run for perhaps 50 accesses to food, enough for the pigeon to maintain body weight near the prescribed level.

Hendry $(1969$, p. 307$)$ presented detailed data on three pigeons that learned to perform the observing response. In subsequent tests of those three, Hendry varied from one experimental session to another the cost of observing the current access price. Those tests showed that each pigeon paid the cost of observation less frequently as the cost increased, in accordance with the demand law.

The results for one pigeon, designated $\mathrm{P}-3$, appear in Figure 1. The vertical axis displays in logarithmic scale the percentage of times the pigeon accepted the chance to observe the current price of access to food. The horizontal axis displays in logarithmic scale the behavioral price of the observation, that is, the required number of pecks on the dark observing key. Thus, in economic terms, Figure 1 displays two consumer demand functions, with quantity consumed $(Q)$ plotted against the unit price of the commodity $(P)$.

One curve shows the demand for observation of the access price when the two possible access prices were 20 and 80 pecks on the food key. Inelastic throughout the four lowest prices $(2,4,8$, and 12 dark-key pecks), the pigeon's demand for access-price observation became elastic when the observation cost moved from 12 to 16 dark-key pecks. Note that with a demand function plotted in logarithmic coordinates, the key to these two categories of elasticity is the slope of the function. If the absolute slope is less than 1, demand is said to be inelastic, but if the absolute slope is greater than 1, demand is said to be elastic. That is, the relative drop in consumption is less or greater than the relative rise in price. Thus,

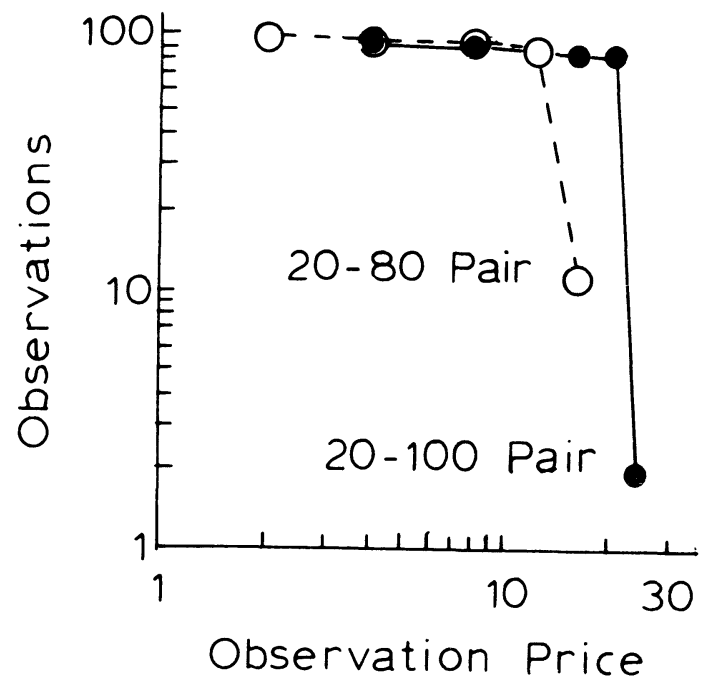

Figure 1. Percentage of times the pigeon accepted the chance to observe the food-access price, as a function of observation price (pecks per observation).
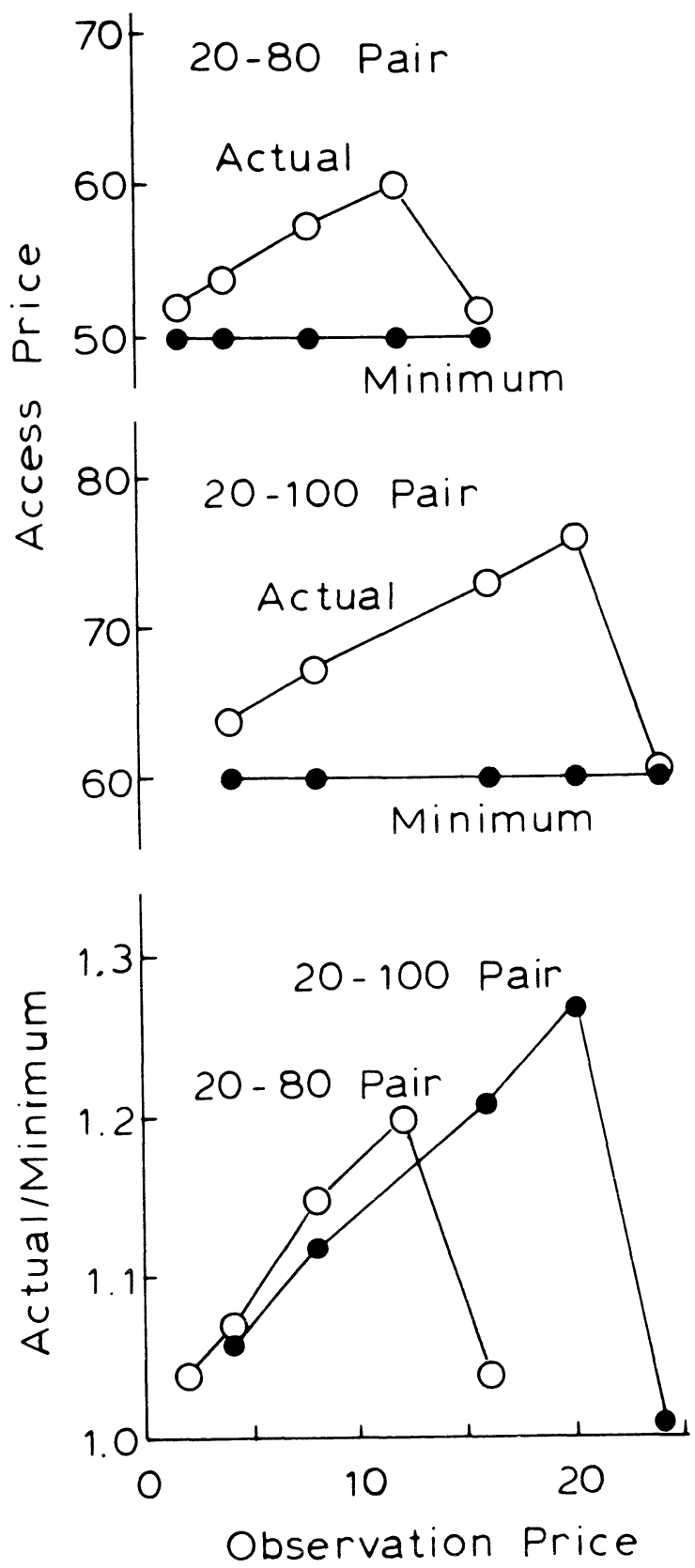

Figure 2. Access price (pecks) as a function of observation price (pecks).

if demand becomes more price-elastic at higher prices, as it typically does, the logarithmic plot of $Q$ against $P$ will steepen as $P$ increases.

The other curve shows the demand for price observation with a more disparate pair of food-key prices, 20 and 100. A comparison of the two curves shows that when the experimenter raised the higher of the two access prices from 80 to 100, the pigeon became more tolerant of high information costs. With the 20-100 pair, the demand for access-price observation remained inelastic throughout a wider range of prices $(4,8,16$, and 20$)$, becoming elas- 
tic only when the price moved from 20 to 24 dark-key pecks.

Animals often approach stimulus change (Dember, 1956; Dember \& Earl, 1957; Fowler, 1965). Perhaps Hendry's pigeons accepted the chance to observe the price of access merely because of the consequent change in the appearance of the keys, from white and dark to both red or both green. But there are two good reasons to suppose that stimulus change was not the decisive consequence. First, if the pigeon were merely buying stimulus change, why should the demand for stimulus change depend on the difference between the two food prices, as the two curves in Figure 1 show? Second, a similar experiment has shown that stimulus change alone does not maintain the behavior. Suppose the pigeon may choose between two observing keys, one informative and the other uninformative. A peck at the informative key changes the key to red or green, depending on the current food-key schedule. A peck at the uninformative key also changes the key to red or green, but does so haphazardly, without regard to the current food-key schedule. Thus, the two observing keys offer the same stimulus change and charge the same behavioral price for the change. If the pigeon is shopping only for stimulus change, it will show no preference for either observing key. Instead, after the pigeon becomes familiar with the two keys it will always choose the informative key, and never the uninformative one (Bower, McLean, \& Meacham, 1966).

Thus, the results reported by Hendry pose a provocative question. Why should the pigeon buy any information about access price? With the cost of information added to the access price, the purchase of information can only raise the price the pigeon pays for access to food.

The behavior of Hendry's P-3 provides a specific example. The top panel in Figure 2 concerns the access prices paid with the 20-80 pair. The "minimum" line at 50 pecks shows the mean nominal price the pigeon would have paid if it had never pecked the dark observing key:

$$
0.5(20+80)=50
$$

food-key pecks per access. The "actual" curve shows the price actually paid by the pigeon, including the nominal cost of the observation. For example, at a nominal cost of 2 pecks per observation, P-3 bought the observation on $95 \%$ of its opportunities (see Figure 1). Thus, the mean price of each access to food was

$$
0.5[.95(2+20+2+80)+.05(20+80)]=51.9
$$

pecks per access.

Note that the "actual" curve is higher throughout than the "minimum" curve. Thus, with the 20-80 pair of access prices, P-3 always paid a higher price per access than it need have done. At the two extremes, the cost the pigeon actually incurred in observing the access price added relatively little to the actual price of access to food. At the leftmost point, the pigeon bought many cheap observations. At the rightmost point, the pigeon bought few expensive observations. But in the middle range, the pigeon's inelastic demand for observation added considerably more to the price of access to food. The middle panel in Figure 2 reveals the same pattern for the other pair of food-key prices, 20 and 100, where the "minimum" line represents 60 pecks.

The bottom panel of Figure 2 facilitates a direct comparison of the two pairs. The vertical axis displays the actual price of access to food, relative to the minimum price (50 or 60 pecks). Note that the two curves nearly coincide when the observation price is relatively low, but soon diverge as the price rises further. At the higher observation prices, the price actually paid for access, relative to the minimum, was considerably greater when the range of possible access prices was large (the 20-100 pair) than when it was small (the 20-80 pair).

How might the puzzle be resolved? To gain further insights into the economic or adaptive significance of the observing response in this kind of setting, it may be helpful to focus on two distinctions often overlooked. One is the distinction between nominal price and actual price. The other is the distinction between access and consumption.

The nominal behavioral price of access to food may differ substantially from the actual behavioral price of the food the pigeon manages to eat. Such experiments typically leave the food-key accessible throughout the entire session-an arrangement that makes it easy for the pigeon to overpay the nominal food-key requirement. Thus, although the food-key schedule may require only 20 pecks, the pigeon is free to emit a variable number of extra pecks at the ever-present key before it moves to the open hopper to collect the food it has just purchased. Most important, such experiments typically use a "limitedhold" procedure whereby the hopper stays open for a certain amount of time, regardless of the amount the pigeon manages to eat during that time. And the experimenter rarely reports the amount of food actually consumed, because the dominant theoretical interpretation of such experiments has viewed access to food as the salient event, the "reinforcing" event.

Method follows interpretation. Method would change if the pigeon were viewed not as a recipient of reinforcement, but as an animal engaged in the search for and consumption of food.

Perhaps the external cues that are contingent on the observing response somehow enable the pigeon to make less overpayment than it does without those cues. Perhaps the pigeon pecks at the food key more efficiently in the presence of those cues than in their absence. Perhaps those cues enable the pigeon to make better use of its access to the hopper than it does without them, to take fuller advantage of its chance to eat. The rat appears capable of a related adaptation: as the behavioral price of water increases, the rat licks more efficiently, taking in more water per lick at higher prices than at lower prices (Allison, Buxton, \& Moore, 1987). Thus, closer attention to the actual behavioral price of the food actually eaten might reveal some economic or adaptive advantage to the observing response that is not yet evident (Dinsmoor, 1985). 


\section{REFERENCES}

Allison, J. (1979). Demand economics and experimental psychology. Behavioral Science, 24, 403-415.

Aluson, J. (1981). Economics and operant conditioning. In P. Harzem \& M. D. Zeiler (Eds.), Advances in analysis of behavior: Vol.2. Predictability, correlation, and contiguity (pp. 321-353). Chichester, England: Wiley.

Allison, J. (1983). Behavioral economics. New York: Praeger.

Allison, J. (1986). Economic interpretations of animal experiments. In A. J. MacFadyen \& H. W. MacFadyen (Eds.), Economic psychology: Intersections in theory and application (pp. 219-245). Amsterdam: North-Holland.

Allison, J., Buxton, A., \& Moore, K. E. (1987). Rats' responses to molar and local schedule constraints. Animal Leaming \& Behavior, $15,360-367$.

Bower, G., Mclean, J., \& Meacham, J. (1966). Value of knowing when reinforcement is due. Journal of Comparative \& Physiological Psychology, 62, 184-192.
Dember, W. N. (1956). Response by the rat to environmental change. Journal of Comparative \& Physiological Psychology, 49, 93-95.

Dember, W. N., EARL, R. W. (1957). Analysis of exploratory, manipulatory, and curiosity behaviors. Psychological Review, 64, 91-96.

Dinsmoor, J. A. (1985). The role of observing and attention in establishing stimulus control. Journal of the Experimental Analysis of Behavior, 43, 365-381.

Fowler, H. (1965). Curiosity and exploratory behavior. New York: Macmillan.

HENDRY, D. P. (1969). Reinforcing value of information: Fixed-ratio schedules. In D. P. Hendry (Ed.), Conditioned reinforcement (pp. 300-341). Homewood, IL: Dorsey.

HURSH, S. R. (1980). Economic concepts for the analysis of behavior. Journal of the Experimental Analysis of Behavior, 34, 219-238.

LEA, S. E. G. (1978). The psychology and economics of demand. Psychological Bulletin, 85, 441-466.

(Manuscript received April 21, 1988.) 